удК 338.32

М. И. Тертышник

Байкальский государственный университет, 2. Иркутск, Российская Федеращия

\title{
СИСТЕМА ПОКАЗАТЕЛЕЙ ОЦЕНКИ ПРОИЗВОДСТВЕННОГО ПОТЕНЦИАЛА ПРЕДПРИЯТИЯ
}

\begin{abstract}
АНнотАЦИя. Производственный потенциал определяется величиной производственных ресурсов предприятия и характеризует его возможности по производству продукции. Определение производственного потенциала необходимо для оценки: величины производственных ресурсов, стоимости предприятия, уровня его конкурентоспособности, научно-технического уровня производства, потенциальных возможностей предприятия, оптимального размера предприятия и других целей. В работе проанализированы существующие подходы к определению производственного потенциала предприятия и сделан вывод, что наибольшее распространение при его оценке получил ресурсный подход. В статье рассмотрены основные виды производственных ресурсов, определяющих производственный потенциал предприятия, рекомендовано дополнительно учитывать в его составе такие виды ресурсов, как оборотные фонды и инновации. Показана взаимосвязь экономического, производственного и инновационного потенциалов предприятия. Предложена классификация показателей оценки основных производственных фондов, которая проведена по семи классификационным признакам. Рассмотрены виды научно-исследовательских работ и опытно-конструкторских разработок, выделены их основные характеристики и особенности. Разработана система показателей оценки оборотных фондов, персонала, технологий, информации, инноваций, как составных элементов производственного потенциала предприятия. Ее использование даст возможность более точно и обоснованно определять величину, состояние и уровень использования производственного потенциала предприятия.

кЛЮчЕВЫЕ СЛОВА. Производственный потенциал; производственные ресурсы; показатели оценки основных фондов; инновационный потенциал; показатели оценки потенциала; показатели оценки инноваций.

ИНФОРМАЦИя О СТАТЬЕ. Дата поступления 10 января 2018 г.; дата принятия к печати 19 марта 2018 г.; дата онлайн-размещения 09 апреля 2018 г.
\end{abstract}

M. I. Tertyshnik Baikal State University, Irkutsk, Russian Federation

\section{THE SCORING SYSTEM OF ASSESSING INDUSTRIAL POTENTIAL OF AN ENTERPRISE}

\begin{abstract}
The production potential is determined by the size of production resources of an enterprise and characterizes its production capacity. Definition of the production potential is necessary for estimating the size of industrial resources, the enterprise value, the level of its competitiveness, the scientific and technical level of manufacture, the performance potential of the enterprise, the optimum size of the enterprise, and for other purposes. The paper analyzes the existing approaches to assessing the production potential of the enterprise and concludes that the resource approach assessed is the most widely used. The article considers the main types of production resources that assess the production potential of the enterprise, it recommends to additionally take into account such types of resources in its composition as revolving funds and innovations. The article presents the correlation of the economic, production and innovation potential of the enterprise; it offers a classification of scoring indicators of basic production funds, which is made according to the seven classification criteria; it considers the types of scientific research and experimental development and highlights their main characteris-
\end{abstract}

(C) М. И. Тертышник, 2018

\section{Baikal Research Journal}


tics and features. The system of assessment indicators is developed for working assets, personnel, technology, information, innovations as the components of the production potential of the enterprise. Its use can provide an opportunity for more accurate and reasonable assessment of the size, state and level of use of the production potential of the enterprise.

KEYWORDS. Production potential; production resources; key asset assessment indicators; innovation potential; capacity assessment indicators; innovation assessment indicators. ARTICLE INFO. Received January 10, 2018; accepted March 19, 2018; available online April 09, 2018.

На уровне предприятий определяются различные виды потенциалов, характеризующие их возможности в той иной сферах деятельности. При этом выделяются: экономический, социально-экономический, инвестиционный, природный, кадровый, трудовой, производственный, ресурсный, инновационный, научно-технический и другие виды потенциалов [1-8].

Важное место в оценке возможностей предприятия занимает определение производственного потенциала. В экономической литературе выделяются следующие подходы, связанной с определением понятия «производственный потенциал»:

- Народнохозяйственный подход, с учетом которого эта категория определяется как элемент национального богатства страны.

- Фондовый (результативный) подход, в этом случае производственный потенциал принимается равным величине производственной мощности предприятия.

- Организационно-экономический подход, с учетом которого производственный потенциал предприятия изучается как система экономических отношений.

- Функциональный подход, при использовании которого производственный потенциал оценивается как способность или возможность предприятия по выпуску продукции.

Ресурсный подход, который базируется на том, что производственный потенциал состоит из определенных производственных ресурсов предприятия. При этом можно выделить два направления рассмотрения этой категории:

- производственный потенциал определяется только производственными ресурсами без учета их взаимосвязей и участия в процессе производства;

- под производственным потенциалом понимается совокупность взаимосвязанных производственных ресурсов предприятия, направленных на производство определенных видов продукции [9; 10].

Самым распространенным является ресурсный подход, в соответствии с которым в состав производственного потенциала предприятия традиционно включаются следующие элементы: основные производственные фонды, персонал предприятия, технологии, информация. Наибольший удельный вес в структуре производственного потенциала занимают основные производственные фонды, оценка, состояние и использование которых характеризуется значительным количеством показателей. Поэтому предлагается провести их классификацию по следующим основным признакам:

1. По стоимости основных фондов на момент их приобретения или эксплуатации.

2. С учетом структуры основных фондов.

2. По этапам расчетного периода определения стоимости основных производственных фондов.

4. С учетом технического состояния основных фондов [11].

5. С учетом процесса воспроизводства основных фондов.

6. По степени использования основных фондов.

7. По уровню пропорциональности и использования производственных мощностей [12; 13$]$.

Классификация показателей оценки основных фондов представлена в табл. 1.

\section{Baikal Research Journal}




\section{Классификация показателей оценки основных фондов}

\begin{tabular}{|c|c|c|}
\hline \begin{tabular}{|c} 
Классификационный \\
признак
\end{tabular} & $\begin{array}{c}\text { Значение классификационного } \\
\text { признака }\end{array}$ & $\begin{array}{c}\text { Показатели оценки } \\
\text { основных фондов }\end{array}$ \\
\hline $\begin{array}{l}\text { По стоимости ос- } \\
\text { новных фондов на } \\
\text { момент их приобре- } \\
\text { тения или эксплуа- } \\
\text { тации }\end{array}$ & $\begin{array}{l}\text { показывает стоимость основных } \\
\text { фондов на момент их приобретения } \\
\text { характеризует стоимость основных } \\
\text { фондов с учетом результатов перео- } \\
\text { ценки их стоимости } \\
\text { показывает стоимость основных } \\
\text { фондов с учетом их износа }\end{array}$ & $\begin{array}{l}\text { первоначальная стоимость } \\
\text { восстановительная стоимость } \\
\text { остаточная стоимость }\end{array}$ \\
\hline $\begin{array}{l}\text { С учетом структуры } \\
\text { основных фондов }\end{array}$ & $\begin{array}{l}\text { характеризует долю стоимости } \\
\text { отдельной группы основных фондов } \\
\text { в их общей стоимости } \\
\text { показывает долю стоимости актив- } \\
\text { ной (пассивной) части основных } \\
\text { фондов в их общей стоимости }\end{array}$ & $\begin{array}{l}\text { удельный вес стоимости отдель- } \\
\text { ной группы основных фондов в } \\
\text { их общей стоимости } \\
\text { удельный вес стоимости актив- } \\
\text { ной (пассивной) части основных } \\
\text { фондов в их общей стоимости } \\
\end{array}$ \\
\hline $\begin{array}{l}\text { По этапам расчетно- } \\
\text { го периода опреде- } \\
\text { ления стоимости } \\
\text { основных фондов }\end{array}$ & $\begin{array}{l}\text { на начало года } \\
\text { в среднем за год } \\
\text { на конец года }\end{array}$ & $\begin{array}{l}\text { стоимость на начало года } \\
\text { среднегодовая стоимость } \\
\text { стоимость на конец года }\end{array}$ \\
\hline $\begin{array}{l}\text { С учетом техниче- } \\
\text { ского состояния } \\
\text { основных фондов }\end{array}$ & $\begin{array}{l}\text { учитывается возрастной состав } \\
\text { основных фондов } \\
\text { показывает уровень износа основ- } \\
\text { ных фондов } \\
\text { учитывают возможность даль- } \\
\text { нейшей эксплуатации основных } \\
\text { фондов }\end{array}$ & $\begin{array}{l}\text { нормативный срок службы, } \\
\text { фактический срок службы } \\
\text { величина износа основных } \\
\text { фондов } \\
\text { коэффициент износа основных } \\
\text { фондов, } \\
\text { коэффициент годности основ- } \\
\text { ных фондов }\end{array}$ \\
\hline $\begin{array}{l}\text { С учетом процесса } \\
\text { воспроизводства } \\
\text { основных фондов }\end{array}$ & $\begin{array}{l}\text { характеризует степень обновления } \\
\text { основных фондов } \\
\text { показывает уровень выбытия ос- } \\
\text { новных фондов } \\
\text { характеризует изменение стоимости } \\
\text { основных фондов в течение года } \\
\text { показывает интенсивность процесса } \\
\text { ввода и выбытия основных фондов } \\
\text { характеризует степень прогрессив- } \\
\text { ности процесса обновления основ- } \\
\text { ных фондов }\end{array}$ & $\begin{array}{l}\text { коэффициент обновления основ- } \\
\text { ных фондов } \\
\text { коэффициент выбытия основ- } \\
\text { ных фондов } \\
\text { коэффициент прироста основ- } \\
\text { ных фондов } \\
\text { коэффициент интенсивности } \\
\text { обновления основных фондов } \\
\text { коэффициент прогрессивности } \\
\text { обновления основных фондов }\end{array}$ \\
\hline $\begin{array}{l}\text { По степени исполь- } \\
\text { зования основных } \\
\text { фондов }\end{array}$ & $\begin{array}{l}\text { отражают общий уровень использо- } \\
\text { вания основных фондов } \\
\text { характеризует использование ос- } \\
\text { новных фондов во времени }\end{array}$ & $\begin{array}{l}\text { фондоотдача, фондоемкость, } \\
\text { машиноотдача, рентабельность } \\
\text { производства } \\
\text { коэффициент сменности }\end{array}$ \\
\hline $\begin{array}{l}\text { По уровню про- } \\
\text { порциональности } \\
\text { и использования } \\
\text { производственных } \\
\text { мощностей }\end{array}$ & $\begin{array}{l}\text { характеризует общий уровень } \\
\text { использования производственных } \\
\text { мощностей } \\
\text { отражает максимально возможный } \\
\text { уровень использования производ- } \\
\text { ственных мощностей с учетом эко- } \\
\text { номически обоснованных резервов } \\
\text { мощностей } \\
\text { показывает пропорциональность } \\
\text { производительности оборудования, } \\
\text { установленного на различных ста- } \\
\text { диях производства }\end{array}$ & $\begin{array}{l}\text { коэффициент использования } \\
\text { производственных мощностей } \\
\text { норматив использования произ- } \\
\text { водственных мощностей }\end{array}$ \\
\hline
\end{tabular}

Проблемным является вопрос об учете в производственном потенциале предприятия других ресурсов (или элементов), например, оборотных фондов,

\section{Baikal Research Journal}


энергии, ресурсов организации производства и управления, инноваций. Оборотные фонды являются производственными ресурсами, но находятся в постоянном движении, что осложняет их учет. Они могут включаться в состав производственного потенциала на предприятиях, которые характеризуются длительным производственным циклом. Энергия также является одним из видов ресурсов, но она может быть учтена только по величине ее потребления, иначе говоря в форме затратной характеристики. Включение в состав производственного потенциала ресурсов организации и управления производством, на наш взгляд, не является вполне обоснованным, т.к. эти виды ресурсов не относятся к числу производственных.

Инновации относятся к числу производственных ресурсов предприятия и тесно связаны с научно-техническим прогрессом и НИОКР $[14 ; 15]$. Для них характерны все виды НИОКР, которые представлены в табл. 2, кроме того они связаны и с процессом производства новой техники или продукции. Поэтому инновации должны учитываться при определении производственного потенциала предприятия.

Таблица 2

Виды научно-исследовательских работ и опытно-конструкторских разработок и их основные характеристики

\begin{tabular}{|c|c|c|}
\hline $\begin{array}{c}\text { Виды } \\
\text { НИОКР }\end{array}$ & $\begin{array}{c}\text { Уровень } \\
\text { реализации }\end{array}$ & $\begin{array}{c}\text { Основные характеристики } \\
\text { и особенности }\end{array}$ \\
\hline $\begin{array}{l}\text { Фундаменталь- } \\
\text { ные исследова- } \\
\text { ния }\end{array}$ & $\begin{array}{l}\text { Научно-исследовательские } \\
\text { институты Российской } \\
\text { академии наук (НИИ } \\
\text { РАН) }\end{array}$ & $\begin{array}{l}\text { Связаны с открытием новых явлений в } \\
\text { развитии природы и общества, созданием } \\
\text { теоретических основ для разработки новых } \\
\text { технологий и новых видов продукции }\end{array}$ \\
\hline $\begin{array}{l}\text { Поисковые ис- } \\
\text { следования }\end{array}$ & $\begin{array}{l}\text { НИИ РАН, осуществля- } \\
\text { ющие фундаментальные } \\
\text { исследования и отрасле- } \\
\text { вые НИИ, проводящие } \\
\text { прикладные исследования } \\
\end{array}$ & $\begin{array}{l}\text { Проводятся с целью определения целесоо- } \\
\text { бразности практической реализации тех или } \\
\text { иных теоретических положений, разработан- } \\
\text { ных в процессе проведения фундаменталь- } \\
\text { ных исследований }\end{array}$ \\
\hline $\begin{array}{l}\text { Прикладные } \\
\text { исследования }\end{array}$ & $\begin{array}{l}\text { Отраслевые НИИ и науч- } \\
\text { ные подразделения круп- } \\
\text { ных предприятий }\end{array}$ & $\begin{array}{l}\text { Направлены на разработку новых видов } \\
\text { техники, технологии и продукции, а также } \\
\text { на существенное совершенствование дей- } \\
\text { ствующих образцов техники, технологии и } \\
\text { продукции }\end{array}$ \\
\hline $\begin{array}{l}\text { Опытно-кон- } \\
\text { структорские } \\
\text { разработки }\end{array}$ & $\begin{array}{l}\text { Отраслевые НИИ и пред- } \\
\text { приятия-заказчики }\end{array}$ & $\begin{array}{l}\text { Предполагают конкретное воплощение } \\
\text { результатов прикладных исследований в } \\
\text { образцы новой техники и технологии, их } \\
\text { внедрение в производство }\end{array}$ \\
\hline
\end{tabular}

Таким образом, при оценке производственного потенциала предлагается дополнительно учитывать такие виды производственных ресурсов, как оборотные фонды и инновации. Состав производственного потенциала предприятия и его взаимосвязь с экономическим и инновационным потенциалами отражены на рис 1. Из данной схемы видно, что производственный потенциал является частью экономического потенциала предприятия и отличается от него на величину финансовых ресурсов. Технология, информация и инновации образуют инновационный потенциал, который входит в состав производственного потенциала предприятия.

Система показателей оценки оборотных фондов, персонала, технологий, информации, инноваций, как составных элементов производственного потенциала предприятия, представлена в табл. 3.

\section{Baikal Research Journal}




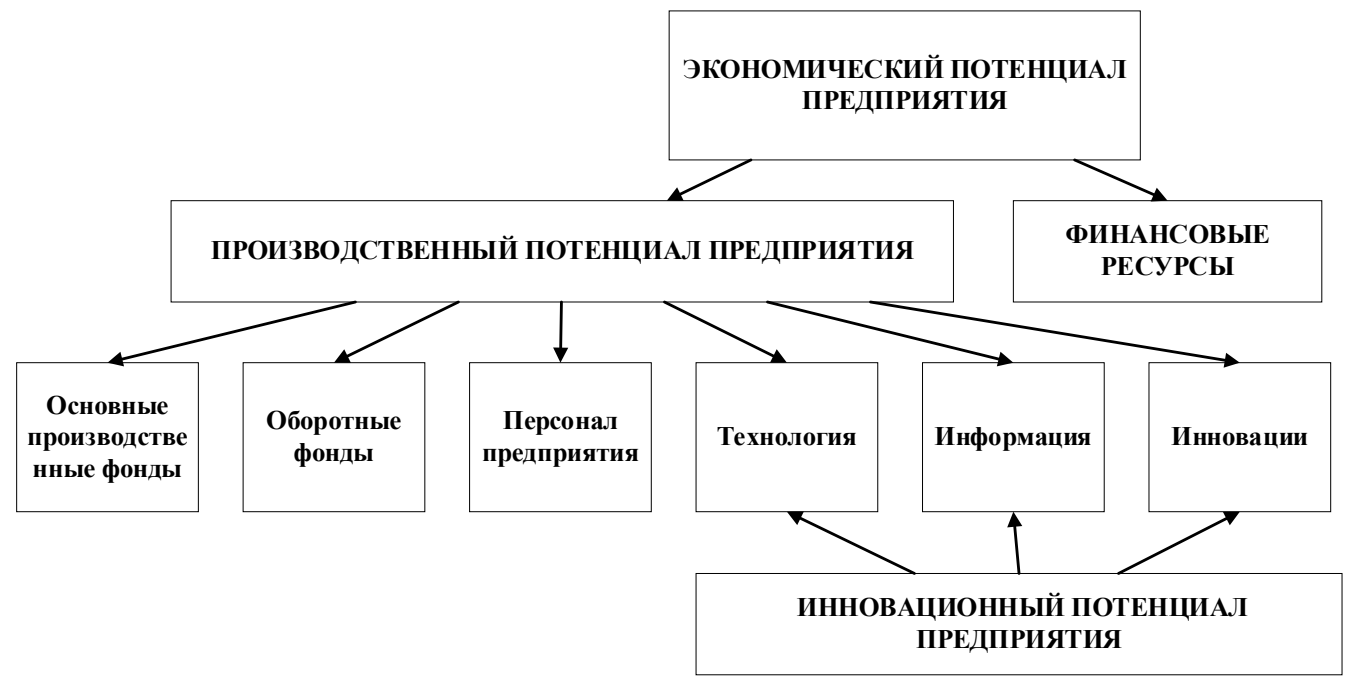

Рис. 1. Состав производственного потенциала предприятия и его взаилосвязь с эконолическил и инновационныл потенциалали

Таблица 3.

Система показателей оценки элементов производственного потенциала предприятия

\begin{tabular}{|c|c|c|}
\hline $\begin{array}{c}\text { Группа } \\
\text { показателей }\end{array}$ & $\begin{array}{c}\text { Наименование } \\
\text { показателей }\end{array}$ & Характеристики показателей \\
\hline $\begin{array}{l}\text { Показате- } \\
\text { ли оценки } \\
\text { оборотных } \\
\text { фондов }\end{array}$ & $\begin{array}{l}\text { коэффициент использования мате- } \\
\text { риальных ресурсов } \\
\text { норма производственного запаса } \\
\text { оборачиваемость оборотных } \\
\text { средств } \\
\text { прямой коэффициент оборачива- } \\
\text { емости } \\
\begin{array}{l}\text { обратный коэффициент оборачи- } \\
\text { ваемости }\end{array}\end{array}$ & $\begin{array}{l}\text { характеризует уровень использования } \\
\text { ресурсов производства } \\
\text { показывает величину необходимого запа- } \\
\text { са производственных ресурсов } \\
\text { характеризует период времени, в тече- } \\
\text { ние которого проходит полный кругообо- } \\
\text { рот оборотных средств } \\
\text { отражает количество оборотов, которое } \\
\text { проходят оборотные средства за анализи- } \\
\text { руемый период времени } \\
\text { показывает фондоемкость оборотных } \\
\text { средств }\end{array}$ \\
\hline $\begin{array}{l}\text { Показатели } \\
\text { оценки пер- } \\
\text { сонала }\end{array}$ & производительность труда & $\begin{array}{l}\text { показывает количество продукции, } \\
\text { производимой работником в единицу } \\
\text { времени } \\
\text { характеризует величину затрат труда на } \\
\text { производство единицы продукции }\end{array}$ \\
\hline $\begin{array}{l}\text { Показатели } \\
\text { оценки тех- } \\
\text { нологий }\end{array}$ & $\begin{array}{l}\text { эффективность технологии произ- } \\
\text { водства } \\
\text { технологическая оснащенность } \\
\text { производства } \\
\text { удельный вес прогрессивных тех- } \\
\text { нологий } \\
\text { коэффициент механизации (авто- } \\
\text { матизации) производства } \\
\text { коэффициент механизации (авто- } \\
\text { матизации) работ } \\
\text { коэффициент механизации (авто- } \\
\text { матизации) труда }\end{array}$ & $\begin{array}{l}\text { отражает объем продукции, произведен- } \\
\text { ной с } 1 \text { р. стоимости технологий } \\
\text { характеризует фондоемкость технологии } \\
\text { производства } \\
\text { показывает долю прогрессивных техно- } \\
\text { логий в общей стоимости технологий } \\
\text { характеризует уровень механизации } \\
\text { (автоматизации) производства } \\
\text { отражает степень механизации (автома- } \\
\text { тизации) работ } \\
\text { показывает уровень механизации (авто- } \\
\text { матизации) труда }\end{array}$ \\
\hline
\end{tabular}

\section{Baikal Research Journal}


Окончание табл. 3

\begin{tabular}{|c|c|c|}
\hline $\begin{array}{c}\text { Группа } \\
\text { показателей }\end{array}$ & $\begin{array}{c}\text { Наименование } \\
\text { показателей }\end{array}$ & Характеристики показателей \\
\hline $\begin{array}{l}\text { Показатели } \\
\text { оценки ин- } \\
\text { формацион- } \\
\text { ных ресурсов }\end{array}$ & $\begin{array}{l}\text { отдача информационных ресурсов } \\
\text { информационная оснащенность }\end{array}$ & $\begin{array}{l}\text { отражает объем продукции, произведен- } \\
\text { ной с } 1 \text { р. стоимости информационных } \\
\text { ресурсов } \\
\text { показывает стоимость информационных } \\
\text { ресурсов, необходимых для выпуска } 1 \text { р. } \\
\text { продукции }\end{array}$ \\
\hline $\begin{array}{l}\text { Показатели } \\
\text { оценки инно- } \\
\text { ваций }\end{array}$ & $\begin{array}{l}\text { удельный вес себестоимости фун- } \\
\text { даментальных работ (опытно-кон- } \\
\text { структорских разработок, поиско- } \\
\text { вых, прикладных работ) в общей } \\
\text { себестоимости работ } \\
\text { патентная чистота работ } \\
\text { удельный вес работ, завершив- } \\
\text { шихся внедрением в производство } \\
\text { удельный вес новой продукции }\end{array}$ & $\begin{array}{l}\text { характеризует направленность науч- } \\
\text { но-исследовательской деятельности } \\
\text { организации } \\
\text { отражает научно-технический уровень } \\
\text { выполняемых работ } \\
\text { показывает долю работ, внедренных в } \\
\text { производство } \\
\text { характеризует долю новой продукции в } \\
\text { общем объеме производства продукции }\end{array}$ \\
\hline
\end{tabular}

Таким образом, считаем, что использование системы показателей оценки производственного потенциала предприятия позволит более точно и обоснованно определять его состояние и уровень использования.

\section{Список использованной литературы}

1. Былков В. Г. Концептуальные основы теории развития трудового потенциала / В. Г. Былков // Известия Иркутской государственной экономической академии. - 2012. № 3. - C. 74-79.

2. Лифшиц А. С. Оценка производственного и коммерческого потенциалов промышленного предприятия / А. С. Лифшиц // Современные наукоемкие технологии. Региональное приложение. - 2016. - № 3. - С. 115-123.

3. Миляева Л. Г. Относительный подход к оценке инновационно-производственного потенциала промышленных предприятий / Л. Г. Миляева // Евразийское научное объединение. - 2017. - Т. 1. - С. 94-97.

4. Петров П. А. Формирование единой методологии контроллинга стратегического потенциала промышленного предприятия / П. А. Петров // Вопросы управления. — 2011. — № 3. - С. $128-137$.

5. Ревуцкий Л. Д. Инвестиционный капитал и инвестиционный потенциал предприятия / Л. Д. Ревуцкий // Московский оценщик. - 2010. — № 6. - С. 7-13.

6. Рогов В. Ю. Геоэкономические аспекты развития регионов / В. Ю. Рогов, М. Л. Багайников // Вестник Забайкальского государственного университета. - 2016. — № 8. C. 11-125.

7. Рыков В. М. Теоретические аспекты сущности производственного потенциала организаций агропромышленного комплекса / В. М. Рыков // Известия Иркутской государственной экономической академии. - 2012. - № 2. - С. 67-70.

8. Шуплецов А. Ф. Создание экспертной системы для оценки потенциала производственного предпринимательства в нефтепереработке и нефтехимии на основе теории нечетких множеств / А. Ф. Шуплецов, Д. В. Буньковский // Известия Иркутской государственной экономической академии. - 2011. - № 3. - С. 82-85.

9. Разинькова О. П. Оценка величины, структуры и эффективности использования производственного потенциала предприятия / О. П. Разинькова // Вестник Тверского государственного технического университета. Серия: Науки об обществе и гуманитарные науки. - 2014. - № 1. - С. 135-144.

10. Тертышник М. И. Потенциальные возможности предприятия: проблемы определения и оценки / М. И. Тертышник // Известия Иркутской государственной эконо-

\section{Baikal Research Journal}


мической академии. - 2015. - Т. 25. — № 4. - C. 613-620. — DOI: 10.17150/19933541.2015.25(4).613-620.

11. Тертышник М. И. Определение итоговой стоимости предприятия и общей величины износа его объектов / М. И. Тертышник // Известия Иркутской государственной экономической академии. - 2010. - № 6. - С. 89-91.

12. Тертышник М. И. Оценка резервов и диспропорций производственных мощностей предприятий / М. И. Тертышник // Инновационные кластеры в цифровой экономике : труды науч.-практ. конф. с междун. участием. - СПб. : Изд-во Политехн. ун-та, 2017. C. $410-415$.

13. Тертышник М. И. Особенности планирования и определения производственных мощностей нефтехимических предприятий / М. И. Тертышник // Известия Иркутской государственной экономической академии. - 2016. - Т. 26. - № 3. - С. 411-418. - DOI: 10.17150/1993-3541.2016.26(3).411-418.

14. Морозов А. В. Производственный потенциал предприятия как основа планирования инновационной деятельности: основные подходы к его анализу и оценке / А. В. Морозов, И. В. Гилязутдинова, С. С. Ахметзянова // Вестник Казанского технологического университета. - 2013. - Т. 16, № 22. - С. 352-357.

15. Тертышник М. И. Оценка научно-технического уровня производства и потенциальных возможностей предприятия / М. И. Тертышник // Промышленная политика в цифровой экономике: проблемы и перспективы: труды науч.-практ. конф. с междун. участием. - СПб. : Изд-во Политехн. ун-та, 2017. - С. 632-637.

\section{Referenses}

1. Bylkov V. G. Conceptual foundations of the theory of development of labor potential. Izvestiya Irkutskoi gosudarstvennoi ekonomicheskoi akademii = Izvestiya of Irkutsk State Economics Academy, 2012, no. 3, pp. 74-79. (In Russian).

2. Lifshits A. S. Evaluation of the productive and commercial potential of the industrial enterprise. Sovremennye naukoemkie tekhnologii. Regional'noe prilozhenie = Modern high technologies. Regional app, 2016, no. 3, pp. 115-123. (In Russian).

3. Milyaeva L. G. Relative approach to the assessment of innovative-productive potential of industrial enterprises. Evraziiskoe nauchnoe ob"edinenie = Eurasian scientific Association, 2017, vol. 1, pp. 94-97. (In Russian).

4. Petrov P. A. Formation of a unified methodology of controlling the strategic potential of industrial enterprises. Voprosy upravleniya = Management Issues, 2011, no. 3, pp. 128137. (In Russian).

5. Revutsky L. D. Investment capital and investment potential enterprise. Moskovskii otsenshchik = Moscow appraiser, 2010, no. 6, pp. 7-13. (In Russian).

6. Rogov V. Y., Bagainikov M. L. Geoeconomic aspects of regions development. Vestnik Zabaikal'skogo gosudarstvennogo universiteta $=$ Vestnik of the Transbaikal State University, 2016, no. 8, pp. 116-125. (In Russian).

7. Rykov V. M. Theoretical aspects of the essence of the production capacities of the organizations of agro-industrial complex. Izvestiya Irkutskoi gosudarstvennoi ekonomicheskoi akademii = Izvestiya of Irkutsk State Economics Academy, 2012, no. 2, pp. 67-70. (In Russian).

8. Shupletzov A. F., Bynkovskiy D. V. Creation of expert system for estimation of industrial entrepreneurship potential in oil refining and petrochemistry on the basis of fuzzy-set theory. Izvestiya Irkutskoi gosudarstvennoi ekonomicheskoi akademii = Izvestiya of Irkutsk State Economics Academy, 2011, no. 3, pp. 82-85. (In Russian).

9. Razinkova O. P. Assessing the size, structure and efficiency of use of productive potential of the enterprise. Vestnik Tverskogo Gosudarstvennogo Universiteta. Seriya: Nauki ob obshchestve $i$ gumanitarnye nauki $=$ Herald of Tver State University. Series: social Sciences and Humanities, 2014, no. 1, pp. 135-144. (In Russian).

10. Tertyshnik M. I. The enterprise's potential: problems of defining and evaluating. Izvestiya Irkutskoy gosudarstvennoy ekonomicheskoy akademii = Izvestiya of Irkutsk State Economics Academy, 2015, vol. 25, no. 4, pp. 613-620. DOI: 10.17150/1993-3541.2015.25(4).613-620. (In Russian).

\section{Baikal Research Journal}


11. Tertyshnik M. I. Determination of total enterprise value and abouting the wear amount of objects. Izvestiya Irkutskoy gosudarstvennoy ekonomicheskoy akademii = Izvestiya of Irkutsk State Economics Academy, 2010, no. 6, pp. 89-91. (In Russian).

12. Tertyshnik M. I. Evaluation of reserves and imbalances in production capacity of enterprises. In Innovation clusters in the digital economy: Proceedings of scientific-practical. Saint Petersburg Polytechnic University Publ., 2017, pp. 410-415. (In Russian).

13. Tertyshnik M. I. Planning and assessing the production capacities of petrochemical enterprises. Izvestiya Irkutskoi gosudarstvennoi ekonomicheskoi akademii $=$ Bulletin of Irkutsk State Economics Academy, 2016, vol. 26, no. 3, pp. 411-418. DOI: 10.17150/19933541.2016.26(3).411-418. (In Russian).

14. Morozov A. V., Gilyazutdinova I. V., Akhmetzyanova S. S. Production potential as a basis for planning of innovation activity: basic approaches to its analysis and evaluation. Vestnik Kazanskogo tekhnologicheskogo Universiteta $=$ Herald of Kazan Technological University, 2013, vol. 16, no. 22, pp. 352-357. (In Russian).

15. Tertyshnik M. I. Evaluation of the scientific and technical level of production and potential capacity of the enterprise. Promyshlennaya politika $v$ tsifrovoi ekonomike: problemy i perspektivy: trudy nauch.-prakt. konf. s mezhdun. uchastiem [Industrial policy in the digital economy: problems and prospects. Proceedings of scientific-practical Conference]. Saint Petersburg Polytechnic University Publ., 2017, pp. 632-637. (In Russian).

\section{Информация об авторе}

Тертышник Михаил Иванович - кандидат экономических наук, доцент, кафедра экономики предприятий и предпринимательской деятельности, Байкальский государственный университет, 664003, г. Иркутск, ул. Ленина, 11, e-mail: mtertyshnik@yandex.ru

\section{Author}

Mikhail I. Tertyshnik - PhD in Economics, Associate Professor, Chair of Enterprise Economy and Entrepreneurship, Baikal State University, 11 Lenin St., 664003, Irkutsk, e-mail: mtertyshnik@yandex.ru.

\section{Для цитирования}

Тертышник М. И. Система показателей оценки производственного потенциала предприятия / М. И. Тертышник // Baikal Research Journal. — 2018. — Т. 9, № 1. — DOI : 10.17150/2411-6262.2018.9(1).10.

\section{For Citation}

Tertyshnik M. I. The Scoring System of Assessing Industrial Potential of an Enterprise. Baikal Research Journal, 2018, vol. 9, no. 1. DOI: 10.17150/2411-6262.2018.9(1).10. (In Russian).

\section{Baikal Research Journal}

